\title{
A perspectiva moderna da hermenêutica dialógica de Gadamer: principais contribuições à hermenêutica bíblica
}

\author{
The modern perspective of Gadamer's dialogical \\ hermeneutics: main contributions to biblical \\ hermeneutics
}

\section{La perspectiva moderna de la hermenéutica dialógica de Gadamer: principales contribuciones a la hermenéutica bíblica}

\author{
Prof. Dr. Nelson Maria Brechó da Silva* \\ * Faculdade João Paulo II \\ Submetido em: 3-2-2021 \\ Doutor em Filosofia pela Pontíficia Uni- \\ Aceito em: 8-5-2021 \\ versidade Católica de São Paulo (PUC) \\ nelson.silva@fajopa.edu.br
}

\begin{abstract}
RESUMO
Este artigo almeja apresentar a hermenêutica contemporânea de Gadamer a partir da hipótese da linguisticidade (Spracblicbleeit) como compreensão dialógica. A hermenêutica está num processo de construção incessantemente e, sobretudo, de forma não harmônica, com a tradição. Assim, deseja-se, com o apoio do comentário de Bleicher, considerar que a ciência e a técnica se desenvolvem por meio da previsibilidade, ao passo que a hermenêutica procura desvendar o não dito, ou seja, a imprevisibilidade, de sorte que a ciência e a técnica são um tipo de saber que não é absoluto. Com efeito, esta visão dialógica envolve a fusão de horizontes capaz de permitir, no âmbito da hermenêutica bíblica, a análise dos efeitos do texto sagrado na sua comunidade, bem como nas pequenas comunidades atuais e nos grupos de pesquisa em Ciências da Religião e de Teologia, que procuram se dedicar ao estudo bíblico. Nesse sentido, ilustra-se como exemplo de aplicação algumas passagens de Cântico dos Cânticos.

Palavras-chaves: História efectual; diálogo; fusão de horizontes; amor; amado.
\end{abstract}

\begin{abstract}
This article aims to present Gadamer's contemporary hermeneutics based on the hypothesis of linguisticity (Spracblicbleeit) as a dialogical understanding. Hermeneutics is in a process of construction ceaselessly and, above all, not in harmony with tradition. Thus, it is desired, with the support of Bleicher's comment, to consider that Science and technique are developed through predictability, while hermeneutics seeks to unveil the spoken, that is, the unpredictability, so that science and technique are a typ of knowledge, which is not absolute.In effect, this dialogical vision invlves the fusion of horizons capable of allowing, within the scope of biblical hermeneutics, the analysis of the effects of the sacred text in tis community, as well as in small communities today and in research groups in Religious Studies and Theology, who seek to dedicate themselves to bible study. In this sense, some passages of Song of Songs are illustrated as an application example.

Keywords: effective history; dialogue; fusion of horizons; love; beloved.
\end{abstract}




\begin{abstract}
RESUMEN
Este artículo tiene como objetivo presentar la hermenéutica contemporánea de Gadamer basada en la hipótesis de la linguística (Spracblicbkeit) como comprensión dialógica. La hermenéutica está en un proceso de construcción incessante y, sobre todo, no en armonía con la tradición. Así, se desea, con el apoyo del comentário de Bleicher, considerar que la ciência y la técnica se desarrollan a través de la previsibilidade, mientras que la hermenéutica busca desvelar lo tácito, es decir, la imprevisibilidad, de modo que la ciencia y la técnica sean un tipo de conocimiento, que no es absoluto. En efecto, esta visión dialógica implica la fusión de horizontes capaces de permitir, en el ámbito de la hermenéutica bíblica, el análises de los efectos del texto sagrado en su comunidade, así como en las pequeñas comnuidades de hoy y en grupos de investigación en Estudios de la Religión y Teología, quienes buscan dedicarce al estudio de la Biblia. En este sentido, algunos pasajes del Cantar de los Cantares se ilustran como ejemplo de aplicación.
\end{abstract}

Palabras clave: historial efectivo; diálogo; fusión de horizontes; amor; amado.

\title{
Introdução
}

Ao discursar sobre a palavra hermenêutica, faz-se mister ver a sua gênese: provém do grego hermeneuein, que significa "anunciar", "explicar" e "traduzir". Esse significado está em articulação com o nome do deus Hermes, que traz as mensagens dos deuses para os mortais. Hermes não tem apenas de anunciar as mensagens divinas, mas também de torná-las compreensíveis. $\mathrm{Na}$ Antiguidade e na Idade Média, a hermenêutica ganha um aspecto exegético e teológico, mas como mero expediente e como um método certamente indispensável à filosofia. Agora, no século XX, a hermenêutica se transforma numa escola própria da filosofia, que indica uma direção própria. O conhecimento que o sujeito realiza com o mundo se dá "mediado pela linguagem. Um conhecimento que se forma no diálogo constante com a tradição: uma revisão que dura toda a vida" (STORIG, 2008, p. 607-608).

Desenvolvem-se, nesta reflexão, três grandes partes: na primeira, elucida-se uma análise do pensamento de Gadamer, filósofo alemão contemporâneo (1900-2002), mais especificamente da terceira parte de sua obra Verdade e Método (v.1), A virada ontológica da hermenêutica no fio condutor da linguagem, que elucida o aspecto hermenêutico sui generis do autor: linguagem como compreensão dialógica. $\mathrm{Na}$ segunda parte, aponta-se o comentário de Bleicher acerca da hermenêutica de Gadamer. Na terceira, sublinham-se as contribuições gadamerianas à hermenêutica bíblica, particularmente a compreensão dialógica e a fusão de horizontes. Para tanto, exemplifica-se com uma análise hermenêutica de Cântico dos Cânticos a respeito de uma leitura ético-antropológica. O resultado a ser obtido é de que a perspectiva moderna de Gadamer pode muito colaborar na revisitação da Bíblia, por intermédio dos estudos bíblicos em pequenas comunidades, bem como nas pesquisas em Ciências da Religião e Teologia. 


\section{Pensamento de Gadamer a respeito da hermenêutica}

$\mathrm{Na}$ hermenêutica de Gadamer, a conversação tem seu próprio espírito e a linguagem que nela se emprega carrega em si sua própria verdade, ou seja, "desvela" e deixa surgir algo inovador. A linguagem é o medium em que se realizam o acordo dos interlocutores e o entendimento sobre a coisa em questão. Pode-se afirmar, com efeito, que a hermenêutica abarca uma dimensão dialógica para maior compreensão do texto.

A conversação é um processo do acordo e, por mais que o tradutor tenha entrado na vida e nos sentimentos do autor, a tradução de um texto não é um mero redespertar do processo anímico original de sua redação, mas "uma reconstituição do texto guiada pela compreensão do que se diz nele" (GADAMER, 2007, p. 499-500). Toda tradução que leva a sério sua tarefa torna-se mais clara e mais fluente que o original. Todo tradutor é intérprete. Tanto no tradutor quanto no intérprete se reconhece "a forma de realização da conversação, graças à qual chega à expressão uma coisa que não é somente minha ou de meu autor, mas uma coisa comum a ambos" (GADAMER, 2007, p. 503). E mais:

A linguagem é o medium universal em que se realiza a própria compreensão. A forma de realização da compreensão é a interpretatio (constatar isso não significa que não haja problemas específicos em relação à expressão). Todo compreender é interpretar, e todo interpretar se desenvolve no medium de uma linguagem que pretende deixar falar o objeto, sendo, ao mesmo tempo, a própria linguagem do intérprete. (GADAMER, 2007, p. 503).

Logo, o objeto primordial da interpretação possui a natureza própria da linguagem. Na escrita, a linguagem se liberta do ato de sua realização. Assim, na forma da escrita, todo o transmitido está simultaneamente presente para qualquer atualidade. O leitor que se aprofunda numa língua e literatura estrangeiras mantém, a todo o momento, a liberdade de voltar de novo a si mesmo, e assim está ao mesmo tempo aqui e acolá. O portador da tradição é "a continuidade da memória. Só se inicia a tarefa hermenêutica quando já houver uma decifração (supostamente correta)" (GADAMER, 2007, p. 506).

A hermenêutica tem como tarefa a compreensão dos textos. De certo modo, o que é fixado por escrito se eleva aos olhos de todos para uma esfera de sentido na qual pode participar todo aquele que esteja em condições de ler. Platão considerava que o desamparo da escrita representava uma debilidade muito maior do que aquela que afeta os discursos (to asthenes tón logón) (GADAMER, 2007, p. 508). ${ }^{1}$ A compreensão é colocada a caminho através da coisa em questão:

1 Todos os filósofos indicados neste tópico "Pensamento de Gadamer a respeito da hermenêutica" são citados por Gadamer. Por esse motivo, utiliza-se a indicação de fonte a obra Verdade e método de Gadamer. 
De fato, todo escrito é por excelência objeto da hermenêutica. Conceitos normativos como a opinião do autor ou a compreensão do leitor originário representam, na realidade, apenas um lugar vazio que se preenche de compreensão, de ocasião para ocasião. (GADAMER, 2007, p. 512).

Por conseguinte, todo escrito tem a pretensão de, autonomamente, despertar e ganhar vida no elemento falado. A própria compreensão possui uma relação fundamental com o caráter de linguagem (GADAMER, 2007, p. 512). Se agora se vê orientado para o caráter de linguagem de toda compreensão, então aquilo que já se demonstrou na dialética de pergunta e resposta é novamente trazido à fala a partir de outro aspecto.

A consciência histórica compreende a si mesma erroneamente, quando, para compreender, pretende descartar a única possibilidade de compreender. $\mathrm{Na}$ verdade, pensar historicamente significa realizar a conversão que acontece aos conceitos do passado quando procuramos pensar neles. Pensar historicamente implica sempre uma mediação entre aqueles conceitos e o próprio pensar. (GADAMER, 2007, p. 514).

Através da interpretação, o texto deve vir à fala. Mas nenhum texto e nenhum livro falam, se não falarem a linguagem que alcance o outro. Assim, a interpretação "deve encontrar a linguagem correta se quiser fazer com que o texto realmente fale" (GADAMER, 2007, p. 514). A realização interpretativa da compreensão nada mais é que a concreção do próprio sentido. Cabe recordar a maneira como se resgata o valor do momento da aplicação, que fora banido por completo da hermenêutica. Vê-se que compreender um texto significa sempre aplicá-lo a nós próprios.

Onde se trata de compreender e interpretar textos de linguagem, a própria interpretação, no medium da própria linguagem, mostra com clareza o que é a compreensão: uma apropriação do que foi dito, de maneira que se converta em propriedade de alguém. A interpretação que se dá na linguagem é a forma da interpretação como tal (GADAMER, 2007, p. 515). Compreender e interpretar estão imbricados de modo indissolúvel.

$\mathrm{O}$ conceito de interpretação não se aplica somente à interpretação científica, mas também à reprodução artística, por exemplo, na execução musical ou cênica. A escrita cifrada na qual se encontra um texto musical ou um drama só é solucionada na interpretação. A leitura contém sempre uma interpretação, de modo que a "interpretação da música ou da poesia, por exemplo, quando executadas, não diferem essencialmente da compreensão de um texto, quando é lido: compreender implica sempre interpretar" (GADAMER, 2007, p. 516-517). 
A visão da imbricação interna entre interpretação e compreensão permite também destruir a falsa romantização da imediatez que artistas e conhecedores cultivaram e cultivam sob o signo da estética do gênio. A interpretação não pretende pôr-se no lugar da obra interpretada. Se toda compreensão se encontra numa necessária relação de equivalência com sua possível interpretação, e se a compreensão não conhece nenhuma barreira fundamental, também a concepção que se dá na linguagem, concepção experimentada pela compreensão na interpretação, precisa conter uma infinitude que supere qualquer fronteira. A linguagem é a linguagem da própria razão.

Como será possível, então, compreender uma tradição estranha se de certo modo o sujeito está atado à língua que fala? É importante perceber que esse raciocínio é aparente. A Filosofia da Linguagem se interessa pela multiplicidade das línguas e que cada língua diz o que quer. O sujeito, de sua parte, coloca "a interpelação de como, dentro da multiplicidade dessas maneiras de falar pode se estabelecer a mesma unidade de pensar e falar, de tal maneira que, a princípio, qualquer tradição escrita possa ser compreendida" (GADAMER, 2007, p. 521). Herder e Humboldt aprenderam a ver as línguas como modos de ver o mundo.

A pergunta que guia é, portanto, a da conceitualidade de toda compreensão. Precisa-se, antes, reconhecer que toda compreensão está intimamente entretecida por conceitos e refutar qualquer teoria que se negue a aceitar a unidade interna de palavra e coisa. No caminho da análise do fenômeno hermenêutico, dá-se de cara "com a função universal do caráter de linguisticidade (Sprachlichkeit)" (GADAMER, 2007, p. 523). Os gregos não possuíam nenhum termo para o que se chama "linguagem", no momento em que a unidade, que se impunha universalmente, entre palavra e coisa, começou a se tornar problemática e digna de ser pensada.

Herder e Humboldt têm o objetivo de estudar como se desenvolve a naturalidade da linguagem humana - uma visão arrancada com dificuldades do racionalismo e da ortodoxia - na amplitude de experiências dentro da diversidade da estruturação da linguagem humana. Reconhecendo em cada língua um organismo, procuram "estudar em sua consideração comparativa a riqueza dos meios de que se serviu o espírito humano para exercer sua capacidade de linguagem" (GADAMER, 2007, p. 566).

O ponto de partida de Humboldt é que as línguas são produtos da "força do espírito" humano (GADAMER, 2007, p. 567-568). Há, evidentemente, graus de diferença na perfeição das línguas. Sabe-se que ele aprendeu a compreender cada língua como uma concepção do mundo própria e o que fazia investigando a forma interior em cada vez que se diferencia o originário 
acontecimento humano da formação da linguagem. O que sustenta esta tese é, primeiramente, a Aufklärung, pois considera o princípio de individuação na aproximação ao verdadeiro e ao perfeito. Segundo, a Metafísica da individualidade desenvolvida por Leibniz. Humboldt segue, portanto, o caminho da abstração rumo à forma.

O que proporciona um novo ponto de vista na própria concepção atual de mundo para Humboldt não é o aprendizado de uma língua estrangeira como tal, mas "seu uso, tanto no trato vivo com pessoas estrangeiras, como no estudo da literatura estrangeira” (GADAMER, 2007, p. 570-571). Ele fala, inclusive, da concepção da linguagem como concepção de mundo. Reconhece, dessa forma, a essência da linguagem, a energeia da linguagem, como a realização viva do falar, rompendo assim com o dogmatismo dos gramáticos. O estar-aí do mundo é constituído pela linguagem. Sendo assim, as línguas são concepções de mundo: "A linguagem é variável no sentido de que existem outras línguas que podem ser aprendidas e também no sentido de que é variável em si mesma, na proporção em que lhe dispõe diversas possibilidades de expressar uma mesma Sach (coisa)" (GADAMER, 2007, p. 574).

A articulação do logos traz à fala a estruturação dos entes, e esse seu trazer à fala, para o pensamento grego, não é outra coisa que a presença do próprio ente, sua alétheia. Nesse sentido, a linguagem representa o rastro da finitude, porque toda língua está em constante formação e desenvolvimento, quanto mais trouxer à fala a sua experiência de mundo. De acordo com Gadamer, "[...] cada palavra irrompe de um centro (Mitte) e se relaciona com um todo, e só é palavra em virtude disso" (GADAMER, 2007, p. 591). Todo falar humano é finito, no sentido de que abriga em si uma infinitude de sentido a ser desenvolvida e interpretada.

A ciência moderna jamais negou completamente sua origem grega, apesar de saber, desde o século XVII, das ilimitadas possibilidades que se abriram para ela. No século XIX, por sua vez, vê-se a dialética. Ainda demonstra continuidade aos problemas de origem grega. Só que um detalhe é imprescindível: o século XIX leva em conta as aporias do subjetivismo! Quanto aos gregos, estes concebem os poderes suprassubjetivos que dominam a história e consideraram o pensamento, desde arché, o princípio, como um momento do próprio ser. Parmênides viu no ser o sinal mais preponderante no trajeto rumo à verdade do ser (GADAMER, 2007).

Para se reconhecer o entrelaçamento do acontecer e do compreender, é necessário retroceder de Hegel até Parmênides. O fenômeno hermenêutico está baseado numa verdadeira primazia do ouvir (Hören), segundo Aristóteles (GADAMER, 2007). 
Segundo Gadamer, "a experiência hermenêutica, enquanto experiência autêntica, deve assumir tudo o que nela se torna presente [...] o acontecido que ela é, ela não pode fazer com que não tenha acontecido" (GADAMER, 2007, p. 597). Hegel critica o conceito de um método que se realiza como uma ação no âmbito da Sach, coisa, onde seria, ao mesmo tempo, alheia a ela. O verdadeiro método seria o fazer da própria Sach. Em relação à compreensão do texto, Gadamer aponta que:

Quem procura compreender um texto precisa ele também manter algumas coisas à distância, a saber, tudo o que se impõe como expectativa de sentido a partir dos próprios preconceitos, na medida em que isso seja negado pelo próprio sentido do texto. (2007, p. 600).

Hegel descreve a relação especulativa do pensar na análise da lógica do enunciado filosófico. Ele mostra que "o enunciado filosófico só é um juízo segundo sua forma exterior, ou seja, atribui um predicado a um conceito de sujeito" (GADAMER, 2007, p. 602). Quando uma frase obriga o pensamento à epoché, suspender o comportamento usual do saber é o que constitui de fato a essência especulativa de toda filosofia. Essa é a essência da filosofia hegeliana! Quanto à distinção entre dialética e o especulativo corresponde ao fato de que a dialética é a expressão do especulativo, a representação do que realmente contém a especulação, e, nesse sentido, é o "realmente" especulativo.

Quem tem algo a dizer "busca e encontra as palavras pelas quais se tornam compreensíveis ao outro" (GADAMER, 2007, p. 605). Na conversação, o falante traz à fala uma relação com o ser. O enunciado poético como tal é especulativo, portanto, na proporção em que o acontecer linguístico da palavra poética expressa uma relação própria com o ser. Conforme Hölderlin, o poema que conseguiu tornar-se obra e criação não é ideal, mas é espírito reanimado a partir da vida infinita (lembra Hegel). A enunciação poética apresenta a nova visão de um novo mundo no âmbito imaginário de invenção poética (GADAMER, 2007).

A interpretação toma parte na discursividade do espírito humano, que somente é capaz de pensar a unidade da coisa no suceder-se de um elemento para o outro. Para Gadamer, “[...] a dialética de pergunta e resposta sempre precede a dialética da interpretação. É aquela que determina a compreensão como um acontecer" (2007, p. 609, itálico nosso). A hermenêutica precisa perceber e atravessar o dogmatismo de todo "sentido em si", como fez a filosofia crítica kantiana em relação ao dogmatismo da experiência (GADAMER, 2007, p. 610). A linguagem do intérprete é, concomitantemente, a manifestação abrangente do caráter de linguagem como tal. 
A linguagem possui uma estrutura especulativa que consiste num vir-à-fala, onde se enuncia um todo de sentido. Agora se aponta para uma estrutura ontológica universal - o ser que pode ser compreendido é linguagem. Fala-se "da linguagem da arte e da natureza e, inclusive, de uma linguagem que as coisas exercem" (GADAMER, 2007, p. 612). O que vem à fala é, naturalmente, algo diferente da própria palavra falada. No entanto, a palavra só é palavra em virtude do que nela vem à fala. A constituição especulativa do ser que subjaz à hermenêutica tem a mesma amplitude universal que a razão e a linguagem.

O conceito do belo, no século XVIII, é semelhante ao sublime na problemática da estética kantiana. Diferentemente será no século XIX, visto que este faz crítica ao metodologismo das ciências do espírito. Aliás, o belo tem estreita relação com o bem (Agathon) da filosofia platônica, acima de tudo, nas obras "Banquete" e "República". Por conseguinte, Aristóteles aponta os momentos (eide) do belo, a ordem (taxis), a correta proporcionalidade (symmetria) e a determinação (borismenon), encontrando esses momentos exemplarmente na matemática (GADAMER, 2007).

Gadamer afirma a respeito da Metafísica do belo o seguinte: primeiro, a relação entre o aparecer do belo. Segundo, evidência do compreensível. Disso decorre o caráter de evento e da hermenêutica que faz experiência da imediatez que sempre caracterizou a experiência do belo e, em geral, de toda evidência da alétheia, verdade. Dessa maneira, notam-se os aspectos da experiência hermenêutica moderna: primeiro, a experiência hermenêutica faz parte do campo do belo, porque ela também é o acontecer de uma autêntica experiência. Segundo, o ser é linguagem, representar-se. Aqui é indispensável aludir uma célebre frase de Tomás de Aquino: "é belo aquilo em cuja contemplação o anseio chega ao seu repouso" (Suma Teológica I, q. 5, a. 4. apud GADAMER, 2007, p. 627).

Além disso, Gadamer postula que “[...] o poeta é um vidente, porque representa por si mesmo o que é, o que foi e o que será, testemunhando por si mesmo o que anuncia" (GADAMER, 2007, p. 628). No poema, o vir-à-fala é como um entrar em relações de taxis, ordem, pelas quais se sustenta e avaliza a verdade do que foi dito. Por esse motivo, a linguagem poética auxilia na compreensão do texto, que, de acordo com Gadamer, compara-se com o belo, de modo que concede um aspecto universal da hermenêutica enquanto processo dialógico:

Quando compreendemos um texto, nos vemos tão atraídos por sua plenitude de sentido como pelo belo. Na medida em que compreendemos, estamos incluídos num acontecer da verdade e quando, de certo modo, queremos saber no que devemos crer, parece-nos que chegamos demasiado tarde. (GADAMER, 2007, p. 631). 
A partir dos dados apresentados, percebe-se o caráter da linguisticidade (Sprachlichkeit), em Gadamer, como determinação do objeto hermenêutico e da realização hermenêutica. Uma determinação que tem como mater lectionis a linguagem como experiência de mundo. Sendo assim, a linguagem é vivenciada e é, sobretudo, um processo permanentemente inacabado, visto que envolve vários conceitos e nuanças para a compreensão, em outras palavras, implica inúmeras teses e discussões. Para se chegar a um acordo linguístico, nota-se que existem os conflitos devido à visão de mundo de cada sujeito. $\mathrm{Na}$ linguagem, é indispensável que venha à tona a pré-compreensão acerca do mundo. Ressalta-se que tal concepção pré-determinada do mundo não é estática e, sim, reivindica a epoché, o distanciamento, ou melhor, a suspensão do juízo para que se faça o levantamento de críticas diante da realidade. Agora, o comentário de Bleicher frente à concepção de linguagem abordada por Gadamer.

\section{Comentário de Bleicher acerca de Gadamer}

Bleicher, no seu livro "Hermenêutica Contemporânea", parte de um esboço introdutório sobre Gadamer, a fim de apontar três seções da hermenêutica gadameriana: primeiro, a historicidade (Geschichtlichkeit) da compreensão; segundo, a compreensão como processo dialógico; terceiro, a linguisticidade (Sprachlichkeit) da compreensão.

De acordo com Bleicher, a linguisticidade do Ser encontra, por um lado, com Gadamer, expressão em conceitos como: Wirkungsgeschichte (história efectual), Zugehorigkeit (pertença), Spiel (jogo) e Gesprach (diálogo) - que são "quase completamente intermutáveis e apontam para a possibilidade da verdade como revelação, ou Horizontverschmelzung (fusão de horizontes)" (BLEICHER, 1980, p. 166). Quanto ao aspecto universal do problema hermenêutico não se refere somente à circunstancialidade histórica da ciência matemática, mas, a fortiori, também às ciências sociais. Aqui, o elemento de co-pertença do intérprete e do objeto é, logicamente, de importância crucial para a determinação da possibilidade do conhecimento objetivo nesta esfera. A filosofia hermenêutica de Gadamer, por outro lado, proporciona o conhecimento da estrutura da compreensão.

A filosofia hermenêutica não incide sobre a metodologia das Geisteswissenschaften, Historicidades da compreensão, e sim sobre a sua relação com toda a experiência do mundo que o sujeito realiza. Ao salientar a compreensão como característica fundamental da existência, não pretende limitar a compreensão disciplinada e específica dos textos, todavia espera, somente, libertá-la de uma 
falsa compreensão pessoal. Como indicam a descrição da fusão de horizontes e a noção de Spiel (jogo), a compreensão só pode resultar da revisão constante do ponto de partida do intérprete, o qual permitirá que o conteúdo venha à superfície. Aliás, a filosofia hermenêutica de Gadamer representa uma gigantesca reorientação da hermenêutica, libertando-a dos condicionalismos que ela impunha a si própria no seu esforço aturado de garantir a objetividade metódica. Desse modo, a filosofia gadameriana enseja e completa a teoria ontológico-existencial da compreensão e, simultaneamente, constitui o pilar da sua superação, mediante a relevância na linguisticidade da compreensão. A partir desse preâmbulo, segue-se o comentário de Bleicher, com o pressuposto da historicidade da compreensão.

Este aspecto é tratado por Gadamer em termos do círculo hermenêutico, com o objetivo de despertar a consciência filosófica das Geisteswissenschaften. Gadamer baseia-se, concomitantemente, na explanação que Heidegger faz da pré-estrutura da compreensão e na tônica de Bultmann na compreensão prévia, na medida em que a primeira é concretizada e a segunda alargada na concepção de "preconceitos", que constituem um determinado "horizonte de compreensão” (BLEICHER, 1980. p. 153-154).

Gadamer, na visão de Bleicher, entende que toda a compreensão é "preconceituosa" e investe um enorme trabalho de pensamento na reabilitação de um conceito que adquiriu a sua conotação negativa com o Aufklärung (BLEICHER, 1980, p. 154). Cabe, por conseguinte, à hermenêutica filosófica realçar o momento histórico na compreensão do mundo e determinar a sua produtividade hermenêutica. Neste sentido, o problema hermenêutico está subjacente a todo o conhecimento.

Constata-se a reapreciação radical que Gadamer faz da situação do intérprete quando é avaliada a existência de preconceitos:

[...] uma pessoa que procura compreender um texto está preparada para que este lhe diga algo. Por isso, uma mente preparada pela hermenêutica deve ser, desde o princípio, sensível à novidade do texto. Mas este tipo de sensibilidade implica a assimilação consciente dos significados prévios e dos preconceitos. O que importa é estar consciente da sua própria predisposição, para que o texto se possa apresentar em toda a sua novidade e conseguir, assim, afirmar, a sua própria verdade, por oposição aos nossos sentidos. (GADAMER apud BLEICHER, 1980, p. 155).

Recorda-se que a teoria hermenêutica insiste na compreensão como uma atividade da subjetividade do intérprete e que melhor se concretizava ao nível de duas mentes em harmonia. Gadamer afirma que "a compreensão não deve tanto ser concebida como uma ação da subjetividade de uma pessoa, 
mas como o inserir-se numa tradição em que passado e presente se fundem constantemente" (GADAMER apud BLEICHER, 1980, p. 156).

Ao confrontar o texto com as suas próprias concepções, o intérprete não visa, como é o lógico, reproduzi-lo no seu estado primitivo; não só o texto representa, em todas as épocas, mais do que a intenção do seu autor, como é também lido em circunstâncias diferentes, sendo, dessa maneira, a compreensão um esforço produtivo (BLEICHER, 1980). Gadamer evidencia os elementos estruturais da Wirkungsgeschichte (história-efectual): o conhecimento da situação hermenêutica especial e do "horizonte" que a caracteriza; relação dialógica entre intérprete e texto; dialética entre pergunta e resposta; abertura à tradição. Gadamer identifica também a história efectual com o "conhecimento hermenêutico", pelo fato de articular simultaneamente o conhecimento da história e a história.

A história efectual representa a possibilidade positiva e produtiva da compreensão. Neste contexto, o intérprete encontra-se na sua própria "situação", a partir da qual tem de compreender a tradição, através dos preconceitos que dela faz provir. O conhecimento das condições prévias fundamentais da compreensão dos efeitos da história efectual é uma condição necessária para o trabalho verdadeiramente científico. Tanto o intérprete como a parte da tradição em que está interessado contêm o seu próprio horizonte. Gadamer chama à elevação da própria particularidade do sujeito e da particularidade do objeto a uma generalidade superior, a "fusão de horizontes".

O intérprete tem, primeiro, consciência de uma distância entre o texto e o seu próprio horizonte, que leva, no processo de compreensão, a um novo horizonte compreensivo que transcende a questão e os preconceitos iniciais. A experiência hermenêutica não implica um desejo de saber tudo, mas, através de uma abertura a novas experiências, "encontra a sua própria realização, não no conhecimento definitivo, mas nessa abertura à experiência, que é encorajada pela própria experiência [...] refere-se à experiência como um todo" (GADAMER apud BLEICHER, 1980, p. 160). A experiência que aqui interessa é a da finitude humana; não implica o mero reconhecimento daquilo que está exatamente neste momento diante do sujeito, mas a consciência das limitações dentro das quais o futuro está ainda aberto às novas perspectivas. Assim, a verdadeira experiência é da própria historicidade inerente ao sujeito (BLEICHER, 1980).

A experiência hermenêutica não é nem monológica, como a ciência, nem dialética, como a história universal de Hegel. Gadamer a elucida como dialógica e não como dialética. Diante dessa asserção, percebe-se que num diálogo se vê a fusão de horizonte, visto que:

ambos se interessam por um objeto que é colocado diante deles. Tal como uma pessoa 
procura chegar a um acordo com o seu parceiro em relação a um objeto, também o intérprete compreende o objeto a que o texto se refere [...] ficando ambos em proveitosa conversa, sob a influência da verdade do objeto e ligados assim um ao outro numa nova comunidade [...] é a transformação numa comunhão, em que deixamos de ser aquilo que éramos. (GADAMER apud BLEICHER, 1980, p. 161).

O que caracteriza esta experiência hermenêutica? A principal tarefa do intérprete é descobrir a pergunta a que o texto vem dar resposta; compreender um texto é compreender a pergunta e isto caracteriza a experiência hermenêutica. Ao se entender a pergunta colocada pelo texto, já foram elaboradas perguntas ao próprio ser e, por conseguinte, abre-se a novas possibilidades de sentido (BLEICHER, 1980).

A linguisticidade da compreensão como articulação do passado e do presente possui a vantagem de constituir um forte argumento contra o ideal de objetividade avançado pelas Geisteswissenschaften. Com isso, a fusão de horizonte é inconcebível sem a intervenção da linguagem. A "viragem ontológica da hermenêutica, sob a orientação da linguagem", retém a sua capacidade penetrante através da incorporação da obra de Heidegger, produzida após a sua famosa "viragem", que melhor se reflete na afirmação de que a "linguagem é a casa do ser" (HEIDEGGER apud BLEICHER, 1980, p. 162).

Gadamer desenvolve o tema do ser "que é trazido à linguagem [...] do ser que chega à linguagem abrindo-se a si mesmo" (GADAMER apud BLEICHER, 1980, p. 163), através da determinação da tarefa da reflexão hermenêutica em relação à linguagem como Mitte (meio), processo, fundamento e solo onde e por intermédio do qual tem lugar o diálogo. As realidades entram na linguagem, de tal modo que não existe um mundo à margem da linguagem.

Constata-se, por meio da explanação de Bleicher, que a fusão dos horizontes pode ser vista agora como "a realização plena da conversação, em que é expresso algo que não é só meu ou do meu autor, mas comum” (GADAMER apud BLEICHER, 1980, 164). O horizonte do intérprete funde-se com o significado de um texto, ou a posição de um colega e é, neste sentido, determinante, sem, no entanto, assumir um ponto de partida fixo. Trata-se, portanto, de uma doxa (opinião) e uma possibilidade que está aberta às mudanças, principalmente quando se encontra com outro "objeto" que lhe afeta. Este é o caminho para que se possa esclarecer um assunto, segundo o pensamento de Gadamer.

\section{Principais contribuições à hermenêutica bíblica}

A hermenêutica filosófica de Gadamer traz várias contribuições a serem desenvolvidas na hermenêutica bíblica, a saber: a visão da linguisticidade 
como processo dialógico e a fusão de horizontes a partir da experiência com o mundo. Dessa forma, o intérprete dialoga com a obra e expressa a sua doxa (opinião). A riqueza da interpretação principia da relação dialógica entre o intérprete e o texto, de maneira que desvenda aquilo que ainda não foi dito no âmbito da historicidade.

A aplicação da fusão de horizontes no estudo de Cântico dos Cânticos, por exemplo, propicia a compreensão deste texto sagrado numa leitura ético-antropológica em que o autor vai reagir contra a desvalorização do ser humano. ${ }^{2}$ Faz-se mister uma base teológica, em virtude de que o amor da mulher foi rejeitado e a obra, por sua vez, tenta recuperar a antropologia de Gênesis. Através da figura da mulher, o autor supera a marginalização do feminino, resgata a sua importância e, consequentemente, mostra que o amor supera tudo isso.

O gênero literário de Cântico dos Cânticos é poético, uma vez que tem como argumento central o amor romântico, erótico e apaixonante. $\mathrm{O}$ contexto histórico remete, provavelmente, ao final do período persa ou início do período helenístico. Todavia, existe a hipótese de datá-lo no período persa (SILVANO, 2014). Em relação às pesquisas arqueológicas, é importante mencionar que foram descobertos vários poemas semelhantes aos que se encontram em Cântico dos Cânticos, particularmente os cânticos de amor egípcios (BARBIERO, 2004).

Nesse sentido, a mensagem teológica de Cântico dos Cânticos corresponde, primeiro, ao amor, que é a força capaz de reger o universo. Segundo, o prazer faz parte da existência humana e esta só tem sentido se for prazerosa. Vale ressaltar a ressignificação em torno da palavra prazer não como algo a ser submetido ao controle e, sim, ao impulso de bem viver a vida. Terceiro, a verdadeira imagem de Deus é a que o apresenta como o Deus do amor e da vida e que deseja ver o ser humano a viver uma vida prazerosa. Supera-se, portanto, a ideia de um Deus castigador. Quarto, do amor divino ao amor humano e vice-versa: amor de Deus - antropomorfizar o seu amor - amor humano. Quinto, a relação homem - mulher, agora, é marcada pela autonomia da mulher (Ct 8.10: "eu sou muralha e meus seios são torres"). ${ }^{3}$ Constata-se que a mulher não é mais passiva. O autor concede ao amor a

2 A reflexão desenvolvida neste ponto "Principais contribuições à hermenêutica bíblica" não pretende fazer uma análise exegética minuciosa de Cântico dos Cânticos e sim uma análise hermenêutica para demonstrar a aplicabilidade da hermenêutica dialógica e da fusão de horizontes de Gadamer nos textos sagrados.

3 Todas as citações bíblicas foram consultadas na edição crítica hebraica: ELLIGER, K; RUDOLPH, W. Biblia Hebraica Stuttgartensia. Stuttgart: Deutsche Bibelgesellschaft, 1997; assim como da edição brasileira: Bíblia. Bíblia de Jerusalém. São Paulo: Paulus, 1995. 
sua verdadeira dimensão. Pode-se refletir, com efeito, na fenomenologia do amor, cujo autor não pensa mais na dominação do homem sobre a mulher, de modo que se revela contra o machismo.

Cântico dos Cânticos oferece uma mistura de cânticos de amor e núpcias. Não se pode negar a relação com as núpcias, nem fazer o livro depender inteiramente delas. $\mathrm{O}$ fato de mencionar a noiva e o casamento indica que as perícopes 3.6-11; 4.8,9-11; 4.12-5.1 são cânticos nupciais, aos quais se devem também juntar pelo menos 1.2-4,9-17; 7.1-6 e 8.5-7. Os outros cânticos são puramente poemas amorosos, como os que se conhecem da poesia egípcia antiga e da poesia oriental mais recente. Frequentemente, os cânticos exaltam o encanto do amor, o anelo recíproco dos que se amam, sua paixão, sua mútua entrega à alegria por causa da união dos dois. Os cânticos celebram em termos efusivos e sensuais o amor que atrai o homem e a mulher aos braços um do outro, com força tão poderosa, que eles não podem resistir (ZENGER, 2003).

Os cânticos não apenas respiram a vida em pulsação, como também estão impregnados da linguagem imaginosa da poesia amorosa que, sob a capa dos simbolismos, utiliza as imagens da vinha, do jardim e da fonte para indicar os atrativos da mulher, e as imagens da comida, da bebida e dos prados para significar o prazer amoroso. A sensualidade em busca da felicidade pressupõe a natureza, cuja descrição emoldura as cenas de amor e, pelo seu caráter idílico e mundano, destaca-se daquela concepção da natureza que se encontra tanto no cântico hínico como na doutrina sapiencial. Além disso, enquanto o cântico descritivo retrata as pessoas à maneira de uma estátua, o poema faz o casal de namorados ou de noivos aparecer veladamente ou sob disfarce literário, inspirado, também este, na poesia egípcia. Assim, termos como "rei" e "rainha", "pastores" e "jardins" seriam disfarces.

Para explicar a forma literária desta obra, recorreu-se frequentemente ao drama amoroso ou à imitação judaica do mimo grego. Esta hipótese ignora a existência dos disfarces literários, tem dificuldade em escolher o personagem masculino principal (rei ou pastor?), é forçada a deixar de lado outras características da mulher (como por exemplo: aldeã ou citadina) e não pode comprovar a existência de uma ação lógica e coerente, nem também um progresso ou uma finalidade para o acontecimento. Portanto, esta hipótese fracassa.

Outra hipótese defende que o livro contém uma descrição homogênea e completa, que vai do primeiro amor até o noivado e ao casamento até à vida matrimonial ou percorre, através de vários diálogos e monólogos, o caminho que vai da admiração pela/o amada/o até a união íntima dos dois. Todavia, estes progressos não são demonstráveis, nem é possível, desta 
forma, encontrar uma unidade à mudança constante dos personagens e das disposições íntimas. Logo, também esta hipótese fracassa.

O Livro teria surgido, pelo contrário, como uma coleção formada por cânticos originalmente autônomos como aqueles cânticos egípcios que se encontram em coleções do mesmo gênero. Sob este aspecto, o livro se assemelha às demais coleções de cânticos do AT, como igualmente a uma grande parte dos livros sapienciais e proféticos. Muitas das repetições levam a supor, também, que o Cântico dos Cânticos surgiu a partir, pelo menos, de duas coleções parciais $(1.15=4.1 ; 2.6-7=8.3-4 ; 2.17 \mathrm{a}=4.6 \mathrm{a} ; 2.17 \mathrm{~b}$ $=8,14)$. A ordem em que os cânticos se sucedem foi determinada, muitas vezes, pela semelhança de conteúdo. $\mathrm{Na}$ maior parte dos casos, esta colocação foi executada, tomando-se as palavras-chave como princípio condutor.

Geralmente, Cântico dos Cânticos é obra considerada popular. O caráter eminentemente literário, a habilidade artística (que não são comum ao camponês e aldeão), o domínio linguístico, a tessitura do poema e as estreitas relações com a poesia egípcia, porém, negam o aspecto popular. Os cânticos, pelo contrário, são poesias artísticas no verdadeiro sentido do termo, isto é, são produções que empregam recursos estilísticos e determinadas pelo sentimento lírico, inclusive, no interior da estrutura fraseológica.

Embora seja uma obra com características peculiares, é classificado tradicionalmente entre os livros sapienciais. A linguagem evoca a literatura sapiencial (cf. por exemplo: Pv 5.15-19; 31.10-31; Eclo 25.13-26.18 e Ct 8.6b-7). Cresce a tendência de se ler a obra conforme o senso literal, devido à compreensão de que o tema do ahavah, amor, humano (que este Livro exalta) não está mais fora de lugar na literatura sapiencial do que o tema da hochmah, sabedoria, humana (de Pv). Em relação ao conteúdo, este livro se enquadra dentro da literatura sapiencial. A atribuição do livro a Salomão (Ct 1.1) - como fora feito com Eclo, Pv e Sb - coloca-o na perspectiva da tradição que vê este personagem como o mélekh hakam, rei sábio, compositor de cânticos (1Rs 5.9-14), aparenta-o com o estilo sapiencial e sugere a ótica que a obra deve ser vista. Isto é confirmado pela localização geográfica em que o livro se encontra, isto é, entre os sapienciais. Portanto, sua classificação canônica é aquela da literatura sapiencial.

É interessante salientar que nos escritos místicos de São João da Cruz, os seus poemas representavam o amor entre Cristo e a Igreja ou o amor entre Deus e aqueles que o buscam. Pode-se sublinhar os versos da canção IX do Cântico Espiritual: 
Por que, pois, hás chagado

Este meu coração, o não saraste?

E, já que mo hás roubado,

Por que assim o deixaste

E não tomas o roubo que roubaste? (SÃO JOÃO DA CRUZ, 1984, p. 631).

A interpretação desta canção permite ver a necessidade de se colocar nas mãos de quem feriu o coração. $O$ remédio consiste no ato de se entregar nos braços do amado para que possa contagiar ainda mais com a força do amor. Nesse sentido, ajuda a entender quando em Cântico dos Cânticos aparecem as expressões hebraicas Dodi "Meu amado" (Ct 5.10) e Re í (Ct 10.16) para designarem o quanto que, diante dos olhos da amada, o amado-amigo é o que ela tem de mais precioso, mais importante e mais sagrado na sua vida. Ela o busca incessantemente, mesmo frente aos desafios da vida, pois o amor ahavah é comparado à mawet morte (Ct 8.6). Ambos são fortes na procura do amado.

A análise hermenêutica de Cântico dos Cânticos, realizada pelo instrumental da fusão de horizontes de Gadamer, enriquece o estudo do feminino no texto sagrado, porque a leitura ético-antropológica possibilita compreender o exercício do amor pautado pela relação recíproca entre homem e mulher. O prazer evoca o sentido do bem viver a vida, em outras palavras, viver intensamente cada momento e descobrir nos traços humanos a presença do divino. Vale recordar que Gadamer comenta que é necessário desvendar o não dito do texto. Assim, Cântico dos Cânticos apresenta o amor humano ligado ao desejo e à paixão (Ct 5.16; 7.11). Pode-se afirmar, com isso, o amor humano como lugar teológico e revelador de Deus.

\section{Considerações finais}

Explanar a respeito da hermenêutica é um assunto enriquecedor. Ainda mais com base num pensador contemporâneo, que leva o sujeito a pensar em face dos anseios que a pós-modernidade suscita no interior dele próprio e nas coisas ao seu redor. Diante disso, constatam-se algumas contribuições de Gadamer à reflexão hodierna. Primordialmente, cabe à hermenêutica a procura de ver os limites da objetividade da Ciência e da Técnica. Cada enunciado linguístico não possui apenas um sentido, pois tudo é ocasional, como por exemplo: a noção de manga como manga de camisa ou como fruta.

O processo hermenêutico é dinâmico, a tal ponto que indica amplitude e ambiguidade. Amplitude no sentido em que amplia incessantemente os horizontes do próprio indivíduo, pois o leva, além de ver outras realidades, a ver 
atentamente a sua própria realidade. É um regressum ad infinitum, porque não é possível o absoluto. A hermenêutica, nesse ponto, é um saber próximo e não filosofia da linguagem. O processo de filosofar adquire um novo sentido, que é linguístico! Antes de se falar da compreensão, precisa-se falar da linguagem não como vestimenta e sim como corpo que ganha forma constantemente.

Quando se diz da ambiguidade hermenêutica, refere-se à dimensão histórica relacionada com a crítica, visto que ela está sempre limitada pelo espaço e pelo tempo, de modo a interpretar os fatos que a rodeiam. Vale mencionar que a hermenêutica está no âmbito da imprevisibilidade de horizonte. Embora os fatos tenham limitações, que se revelam como resistências por parte do sujeito diante daquilo que pode ser desvendado, a hermenêutica não pode desistir da sua missão. As resistências são importantes, porque a hermenêutica não prega a harmonia e o esclarecimento, mas desvenda o não-dito.

Por conseguinte, hermenêutica não é teleológica e sim interpretativa. A sua tarefa crítica, de acordo com o comentário de Bleicher sobre Gadamer, é explicitar os dados inerentes ao mundo. Com isso, a ciência só é mais um tipo de saber aos hermeneutas. A linguagem científica é um momento e não o absoluto. Por essa razão, percebe-se que a linguagem obtém com Gadamer um estilo de compreensão dialógica, que não tem que ser necessariamente pacífica, mas que engloba conflitos e estes fazem parte do mundo. Se o sujeito permanecer no patamar da previsibilidade proposta pela Ciência e pela Técnica, ele ficará obsoleto da linguagem. Isso não significa que se deve descartar o saber científico, mas, sim, matizá-lo como um tipo de saber conforme afirmado anteriormente. Disso decorre que a hermenêutica enseja desvendar o não dito. Ela se demonstra, consequentemente, com um aspecto universal: processo dialógico constante com a tradição.

Quando, na literatura do Primeiro Testamento, é lançado o tema do amor entre homem e mulher, essa abordagem acontece, sobretudo para gerar descendência no contexto de uma sociedade estruturada de modo preponderantemente patriarcal. O Cântico dos Cânticos representa uma exceção. Nele, o amor erótico-sexual entre homem e mulher, independentemente das exigências sem dúvida legítimas da sociedade, é cantado como um poder que obedece às suas próprias leis. A consideração de Cântico dos Cânticos na Sagrada Escritura poderá, assim, preservar, biblicamente orientadas, uma antropologia e uma doutrina da sexualidade humana da fixação patriarcal; de um direcionamento unilateral para gerar descendência; e da observância exagerada de aspectos jurídicos.

Com a valorização e admiração do corpo do homem e da mulher, o autor se posiciona diametralmente contra toda cultura que hostiliza o corpo 
e o amor. Ao voltar a refletir sobre o significado original, as comunidades poderão ser vitoriosas em superar tendências hostis ao corpo e ao amor de sua própria história.

A visão do amor humano no Cântico dos Cânticos pode ser resumida em quatro proposições: o amor humano é uma realidade profunda e intrinsecamente bela e boa; o amor humano é uma realidade terrestre; a experiência amorosa se funda numa relação de igualdade e de mutualidade; o amor tem sua justificação em si mesmo.

À medida que se olha à realidade, percebe-se que o amor, muitas vezes, é confundido com a paixão. Mas, vendo a mensagem do Ct, constata-se que o amor é bem maior do que a paixão. Aquele que ama, deseja o crescimento do próximo. Assim, ao amar, conhece-se a Deus, pois este possui o amor infinito e que convida a pessoa, a cada instante, a participar desse imenso amor que ele tem. Nisso, entende-se que o amor é mais forte do que a morte, pois quem ama vive eternamente nos braços do Pai, de modo que experimenta o mistério de Deus, nutre e participa do seu magnificente amor.

O amor humano como é descrito em Cântico dos Cânticos se torna um lugar teológico revelador da maneira pela qual Deus ama as suas criaturas. Conhecer o amor humano descrito é, especialmente, conhecer os traços do amor de Deus. O amor humano tem sua fonte e sua inspiração no amor de Deus.

Enfim, a perspectiva moderna da hermenêutica dialógica de Gadamer, acima de tudo a fusão de horizontes, corrobora a leitura ético-antropológica de Cântico dos Cânticos de realçar a relevância do amor humano como meio de melhor compreender a experiência divina no humano. É imprescindível afirmar que o instrumental teórico de Gadamer pode, também, auxiliar a hermenêutica bíblica na revisitação de outros textos sagrados.

\section{Referências bibliográficas}

BARBIERO, G. Cantico dei Cantici: nuova versione, introduzione e comento. Milão: Paoline, 2004, p. 38-45. (I Libri Biblici, Primi Testamento, 24).

Bíblia. Bíblia de Jerusalém. São Paulo: Paulus, 1995.

BLEICHER, J. Hermenêutica contemporânea. Rio de Janeiro: Edições 70, 1980, p. 153-179.

ELLIGER, K; RUDOLPH, W. Biblia Hebraica Stuttgartensia. 5. aufl. Stuttgart: Deutsche Bibelgesellschaft, 1997.

GADAMER, H. G. Verdade e método. 8. ed. Trad. Flávio Paulo Meurer. Petrópolis, RJ; Bragança Paulista, SP: Vozes; Editora Universitária São Francisco, 2007, p. 495-631. [título original: Warbeit und methode].

SÃO JOÃO DA CRUZ. Obras completas. Petrópolis: Vozes, 1984. 
SILVANO, Z. Introdução à análise poética de textos bíblicos. São Paulo: Paulinas, 2014. (Bíblia como Literatura, 5).

STADELMANN, L. J. I. Cântico dos Cânticos. São Paulo: Loyola, 1993.

STORIG, H. J. História geral da filosofia. Petrópolis, RJ: Vozes, 2008. p. 607-608.

ZENGER, E. O Cântico dos Cânticos. In: ZENGER, E. (ed.). Introdução ao Antigo Testamento. São Paulo: Loyola, 2003, p. 283-291. 